\title{
INFLUÊNCIA DO CÁLCIO NA TOLERÂNCIA DO MILHO "SARACURA" BRS-4154 AO ENCHARCAMENTO DO SOLO
}

\author{
PAULO CÉSAR MAGALHÃES ${ }^{1}$, JORGE LUIS ROMERO FERRER ${ }^{2}$, JOSÉ DONIZETI ALVES ${ }^{3}$, \\ CARLOS ALBERTO VASCONCELLOS ${ }^{1}$ e FERNANDO RODRIGO DE OLIVEIRA CANTÃO ${ }^{4}$
}

\author{
${ }^{1}$ Eng $^{\circ}$ Agrônomo, PhD, bolsista do CNPq, pesquisador da Embrapa Milho e Sorgo, Caixa postal 151, $35701-970$ - Sete \\ Lagoas-MG.E-mail: pcesar@cnpms.embrapa,br \\ ${ }^{2}$ Engo Agrônomo, MSc, Corpoica - Colômbia. E-mail: jorgeromeroferrer@yahoo.com \\ ${ }^{3}$ Eng $^{\circ}$ Agrônomo, DSc, Professor Depto.de Fisiologia,UFLA. Email: jdalves@ufla.br \\ ${ }^{4}$ Eng ${ }^{o}$ Agrônomo MSc, Bolsista Fapemig, Email: fernandocantao@yahoo.com.br
}

Revista Brasileira de Milho e Sorgo, v.6, n.1, p.40-49, 2007

\begin{abstract}
RESUMO - O milho "Saracura” BRS-4154 apresenta-se como uma opção válida para as várzeas sujeitas ao encharcamento temporário. Pesquisas em laboratório têm demonstrado que a presença de $\mathrm{CaCl}_{2}$ no ambiente de germinação alagado aumenta a tolerância do milho "Saracura". No entanto, esses ensaios foram realizados em condições controladas, nas fases de germinação e desenvolvimento inicial das plântulas. Não existem, até o momento, pesquisas que mostrem a influência do cálcio na tolerância ao longo do desenvolvimento das plantas de milho no campo. Assim, o objetivo deste trabalho foi avaliar o efeito de diferentes níveis, fontes e modos de aplicação do cálcio em condições de encharcamento, no desenvolvimento e rendimento do milho "Saracura", em várzea com drenagem deficiente. Os tratamentos utilizados foram: fontes e doses de cálcio $\left(\mathrm{CaCl}_{2}\right.$, $300,0 \mathrm{~kg} \mathrm{ha}^{-1}$ e gesso, 500,0 e 1500,0 kg ha' ${ }^{-1}$ e formas de aplicação (incorporado nos primeiros $8,0 \mathrm{~cm}$ da superfície, em todo o solo e sobre a superfície). Esses tratamentos foram testados em condições normais de irrigação e sob encharcamento imposto a partir do estádio fenológico V6 até a maturidade fisiológica. Utilizou-se um delineamento de blocos ao acaso, com quatro repetições, avaliando-se, na colheita, as variáveis relacionadas ao crescimento e desenvolvimento, assim como variáveis do rendimento e seus componentes. Dentro de cada ambiente, não foram detectadas diferenças significativas nas variáveis avaliadas, provavelmente devido aos teores de cálcio presentes no solo, o que foi suficiente para garantir o crescimento e desenvolvimento das plantas. No entanto, quando se compararam as características entre ambientes, foi possível detectar superioridade daquelas oriundas da irrigação normal em relação às variáveis do encharcamento.
\end{abstract}

Palavras-chave: alagamento, tolerância, cálcio, milho "Saracura".

\section{EFFECTS OF CALCIUM ON THE TOLERANCE OF SARACURA MAIZE BRS- 4154 UNDER SOIL FLOODING CONDITIONS}

\begin{abstract}
The Saracura maize BRS - 4154 was introduced as an alternative for swamp land areas subjected to temporary flooding. Evidences are usually obtained with $\mathrm{CaCl}_{2}$ presence in flooding germination buffer which increases the tolerance of Saracura. However, such experiments were carried out in controlled conditions, during germination and initial development phases of seedlings. There have been no papers, so far, showing
\end{abstract}


the influence of calcium during the maize development cultivated at field conditions. Therefore, the objective of this research was to evaluate, during the vegetative and reproductive development of Saracura maize, the effect of different levels, sources and mode of calcium application in flooding conditions. For this purpose, this experiment conducted in field conditions. The following treatments were used: calcium sources and dosages $\left(\mathrm{CaCl}_{2}, 300.0 \mathrm{~kg} \cdot \mathrm{ha}^{-1}\right.$ and gypsum, 500.0 and $\left.1500.0 \mathrm{~kg} \cdot \mathrm{ha}^{-1}\right)$ and ways of application (incorporated in the first $8.0 \mathrm{~cm}$ from surface, on the entire soil profile and on surface), in normal irrigation and under flooding conditions imposed at V6 growth stage throughout physiological maturity. A fully randomized block design with four replications was used, and the evaluations were accomplished at harvesting by analyzing traits related to growth and development, as well as yield and its components. Considering each environment it was not able to detect statistic differences among the variables, probably due the calcium content in soil which was sufficient for plant growth and development. However, when one compares characteristics between environments it was possible to detect higher effect from regular irrigation compared to flooding.

Key words: Flooding, tolerance, calcium, "Saracura" maize.

Cerca de 6,0\% da superfície terrestre estão sujeitos ao encharcamento temporário, sendo que, no Brasil, aproximadamente 33 milhões de hectares são de várzeas (solos aluviais e hidromórficos), dos quais cerca de 12 milhões estão localizados na região dos Cerrados (Santos, 1999). Para fazer uso racional dessas áreas, visando ao aumento da produção de grãos, é necessário identificar espécies tolerantes e estudar mecanismos para sobreviver nesse meio.

A cultura do milho apresenta-se como uma opção válida para as várzeas sujeitas a encharcamento temporário. A Embrapa Milho e Sorgo, atenta a essa possibilidade, após 11 anos de estudos, lançou no mercado, em 1997, a cultivar BRS-4154, comumente conhecida como "Saracura", que possui como principal característica tolerância a períodos intermitentes de encharcamento do solo (Parentoni et al., 1995). Posteriormente a esse evento, vários trabalhos foram conduzidos em campo e em casa-de-vegetação, objetivando elucidar os mecanismos de tolerância do "Saracura". Os resultados encontrados apontaram para a porosidade de raízes como prin- cipal característica responsável pela tolerância do "Saracura" ao encharcamento intermitente do solo (Coelho 2004, Magalhães et al. 2000, Magalhães et al. 2001, e Magalhães et al. 2006 ).

A partir daí, surgiu o interesse pelo papel do cálcio na tolerância ao encharcamento do solo, tomando-se como base aqueles trabalhos que relacionaram a maior tolerância à baixa pressão de oxigênio com o metabolismo de parede celular. Ficou comprovada, portanto, a necessidade de verificar qual a participação do cálcio nesse mecanismo, visto que esse íon atua como elemento estrutural, conferindo maior resistência à parede celular (Damarty et al., 1984; Grant et al., 1973).

Trabalhos conduzidos na Universidade Federal de Lavras mostraram que a adição de cloreto de cálcio à solução de germinação promoveu o aumento na sobrevivência das plântulas, sob condições de hipoxia, tanto do "Saracura" como também da variedade BR-107, classificada como não-tolerante a este tipo de estresse (Gouvêa, 2001; Purcino et al., 2001b; Vitorino et al., 2001). Apesar de a adição de cálcio à solução de germinação ter aumentado a tolerância do 
"Saracura" quando em condições de déficit de oxigênio, todos os experimentos realizados até o momento foram conduzidos em laboratório, nas fases de germinação e desenvolvimento inicial das plântulas. Pelo exposto, identificou-se a necessidade de maiores investigações sobre como esse elemento influencia a tolerância ao encharcamento em condições de campo. Assim, o objetivo deste trabalho foi avaliar os efeitos de diferentes níveis, fontes e formas de aplicação do cálcio em condições de encharcamento, no desenvolvimento e na produção do milho "Saracura" cultivado no campo.

\section{Material e Métodos}

Esta pesquisa foi conduzida na área experimental da Embrapa Milho e Sorgo, localizada no município de Sete Lagoas, MG, com altitude de $732,0 \mathrm{~m}$, latitude Sul $19^{\circ} 28^{\prime}$, longitude Oeste $44^{\circ} 15^{\prime}$.

As temperaturas máxima e mínima registradas durante o período de avaliação foram de $32,0^{\circ} \mathrm{C}$ e $14,0^{\circ} \mathrm{C}$, respectivamente. A umidade relativa média foi de $69,0 \%$ e a precipitação acumulada foi de 547,3 mm (Fonte: Estação climatológica - Embrapa Milho e Sorgo).

O solo utilizado neste estudo foi classificado como Neossolo Flúvico Tb, Eutrópico Típico, textura argilosa, fase relevo plano campos de várzea (Sistema, 1999).

Com a finalidade de facilitar o encharcamento, a área foi nivelada e dividida em talhões. As parcelas foram constituídas de cinco fileiras com seis metros de comprimento, com 0,9 metro de espaçamento entre linhas, numa densidade de cinco sementes por metro linear da variedade Saracura - BRS 4154. A adubação foi feita de acordo com os resultados da análise química do solo (Tabela 1). No plantio, foram aplicados 400,0 kg.ha-1 da formulação 05-20-20+Zn, e mais duas adubações de cobertura com 20,0 $\mathrm{g} \mathrm{m}^{-1}$ de sulfato de amônio, nos estádios fenológicos V6 e V8.

Os tratamentos foram constituídos por uma variação de fontes e doses de cálcio $\left(\mathrm{CaCl}_{2}\right.$, na dose de 300,0 $\mathrm{kg} \mathrm{ha}^{-1}$ e gesso, com 500,0 e $1500,0 \mathrm{~kg} \mathrm{ha}^{-1}$ ) e formas de aplicação (incorporado aos primeiros $8,0 \mathrm{~cm}$ da superfície, incorporado em todo o solo e sem incorporar). As plantas foram submetidas a dois ambientes, condições normais de irrigação e encharcamento do solo.

Esse encharcamento foi iniciado no estádio fenológico V6 (caracterizado por seis folhas totalmente desenvolvidas) até a maturidade fisiológica (estádio R6), recebendo uma lâmina de $20,0 \mathrm{~cm}$, por meio de uma inundação de tabuleiro, três vezes por semana. As variáveis de crescimento e desenvolvimento analisadas foram altura da planta, altura de inserção da primeira espiga, diâmetro do caule, e as de rendimento foram rendimento de grão e seus componentes.

O delineamento experimental utilizado foi o de blocos ao acaso, com quatro repetições. Os dados obtidos foram submetidos à análise de variância e as médias, comparadas pelo teste de Tukey, a 5\% de probabilidade.

TABELA 1. Análise química do solo da área experimental da Embrapa Milho e Sorgo.

\begin{tabular}{lllllllll}
\hline $\mathbf{p H}$ & $\mathbf{H}+\mathbf{A l}$ & $\mathbf{A l}$ & $\mathbf{C a}$ & $\mathbf{M g}$ & $\mathbf{K}$ & $\mathbf{P}$ & M.O. & Sat. Al \\
& $---------\mathrm{cmol}_{\mathrm{c}} \mathrm{dm}^{-3}$ & -------- & --- & $\mathrm{mg} \mathrm{dm}^{-3}--$ & $\mathrm{dag} \mathrm{kg}^{-1}$ & $\%$ \\
5,7 & 2,13 & 0,00 & 3,28 & 0,66 & 86,00 & 3,00 & 3,56 & 0,00 \\
\hline
\end{tabular}




\section{Resultados e Discussão}

As variáveis de crescimento e desenvolvimento, altura de planta, altura da primeira espiga e diâmetro do caule, medidas em plantas submetidas à irrigação normal e ao encharcamento, independente dos níveis, fontes e formas de aplicação, não mostraram diferenças significativas em relação às testemunhas. As plantas submetidas ao encharcamento, para as mesmas variáveis citadas anteriormente, apresentaram valores menores do que aquelas cultivadas com irrigação normal (Tabela 2).

A análise de solo revelou um teor de cálcio de $3,28 \mathrm{cmol}_{\mathrm{c}} \mathrm{dm}^{-3}$, considerado um valor médio a adequado para o crescimento e desenvolvimento da cultura do milho (Ribeiro, 1999).
Esses resultados, assim como os teores de cálcio contidos na água usada para irrigação (200,0 mg $\mathrm{L}^{-1}$ ), podem explicar a ausência de resposta em relação à aplicação do cálcio. Ao se comparar os tratamentos encharcados com os irrigados, observaram-se diferenças significativas para as variáveis altura da planta, altura da primeira espiga e diâmetro do caule, podendo deduzir que o encharcamento reduziu o crescimento das plantas. Isso pode ser explicado pela menor energia produzida pelas plantas ao seguirem rotas alternativas para suprir a atividade metabólica, quando submetidas ao estresse por deficiência de oxigênio, levando a uma diminuição do crescimento vegetativo (Alves et al., 2000; Fries et al. 2007; Liao \& Lin, 2001; Summers et al., 2000).

TABELA 2. Altura da planta $(\mathrm{cm})$, altura da primeira espiga $(\mathrm{cm})$ e diâmetro do caule $(\mathrm{mm})$ de plantas de milho "Saracura" no momento da colheita, submetidas ao encharcamento e irrigação normal, com diferentes níveis, fontes e formas de aplicação do cálcio.

\begin{tabular}{|c|c|c|c|c|c|c|}
\hline \multirow{2}{*}{ Tratamento } & \multicolumn{2}{|c|}{ Altura da planta } & \multicolumn{2}{|c|}{$\begin{array}{c}\text { Altura de espiga } \\
\text { Ambiente }\end{array}$} & \multicolumn{2}{|c|}{ Diâmetro do caule } \\
\hline & Encharcado & Irrigado & Encharcado & Irrigado & Encharcado & Irrigado \\
\hline 1 & 163,1 a A & 218,2 a B & 95,7 a $\mathrm{A}$ & 121,0 a B & 13,0 a $\mathrm{A}$ & 15,7 a B \\
\hline 2 & 175,3 a $A$ & 221,0 a B & 101,5 a A & 126,2 a B & 13,7 a $A$ & 16,0 a B \\
\hline 3 & 174,7 a $\mathrm{A}$ & 219,5 a B & 93,7 a $A$ & 127,2 a B & 13,5 a $A$ & 15,5 a $B$ \\
\hline 4 & 183,0 a $\mathrm{A}$ & 226,7 a B & 107,3 a A & 130,7 a B & 14,2 a $\mathrm{A}$ & 15,2 a B \\
\hline 5 & 199,9 a A & 221,0 a B & 98,7 a $A$ & 126,0 a B & 13,7 a $\mathrm{A}$ & 15,4 a B \\
\hline 6 & 202,9 a A & 221,3 a B & 104,7 a A & 125,5 a B & 14,0 a $\mathrm{A}$ & 15,7 a B \\
\hline 7 & 175,5 a A & 215,3 a B & 98,5 a $\mathrm{A}$ & 120,2 a B & 13,7 a $A$ & 14,7 a B \\
\hline 8 & 185,6 a $\mathrm{A}$ & 221,7 a B & 89,2 a $A$ & 121,7 a B & 13,0 a $\mathrm{A}$ & 15,7 a B \\
\hline 9 & 199,2 a A & 219,5 a B & 110,4 a A & 129,0 a B & 14,5 a $\mathrm{A}$ & 15,7 a B \\
\hline 10 & 183,2 a A & 228,7 a B & 93,2 a A & 133,7 a B & 13,2 a $A$ & 15,2 a B \\
\hline CV (\%) & 10,77 & 3,51 & 12,93 & 5,52 & 8,8 & 5,67 \\
\hline
\end{tabular}

Médias seguidas pela mesma letra minúscula, na coluna, e maiúscula, na linha, para cada característica dentro dos diferentes ambientes, não diferem entre si pelo teste e Tukey a $5 \%$.

Tratamentos: ${ }^{1}$ ) Sem Cálcio (testemunha); ${ }^{2}$ ) 500,0 $\mathrm{kg} \mathrm{ha}^{-1}$ de gesso - incorporado a 8,0 cm da superfície; $\left.{ }^{3}\right) 500,0 \mathrm{~kg}$ ha ${ }^{1}$ de gesso - incorporado em todo o solo; ${ }^{4}$ ) 500,0 $\mathrm{kg} \mathrm{ha}^{-1}$ de gesso - sem incorporar; ${ }^{5}$ ) 1500,0 $\mathrm{kg}^{\text {ha-1 }}$ de gesso incorporado a 8,0 cm da superfície; ${ }^{6}$ ) $1500,0 \mathrm{~kg} \mathrm{ha}^{-1}$ de gesso - incorporado em todo o solo; ${ }^{7}$ ) $1500,0 \mathrm{~kg} \mathrm{ha}^{-1} \mathrm{de}$ gesso - sem incorporar; ${ }^{8}$ ) 300,0 kg de cloreto de Cálcio - incorporado a 8,0 cm da superfície; ${ }^{9}$ ) 300,0 kg de cloreto de Cálcio - incorporado em todo o solo; ${ }^{10}$ ) 300,0 kg de cloreto de Cálcio - sem incorporar. 
Para as variáveis de rendimento, peso do grão (Peso de grãos), número de grãos por fileira (Grãos por fileira) e peso de 1000 grãos (Peso de 1000 grãos), a aplicação do cálcio, independente dos níveis, fontes e formas de aplicação no solo, também não mostrou diferenças significativas em relação às testemunhas quando as plantas foram cultivadas sob condições tanto de irrigação quanto de encharcamento (Tabela 3).

Com relação ao índice de espiga (Índice de espiga), Tabela 3 , como observado para as demais variáveis do rendimento, não houve diferenças significativas entre os tratamentos nos dois ambientes. Isso pode ser explicado pelo fato de o milho "Saracura" ser uma variedade selecionada por meio de vários ciclos de seleção massal, partindo de uma mistura de 36 populações diferentes, sob encharcamento, o que propicia uma forte estabilidade genética (Parentoni et al., 1995, Parentoni et al., 1998).

O número de grãos abortados (Grãos abortados) aumentou nas plantas sob condição de encharcamento, Tabela 3. Esse resultado concorda com o trabalho de Souza et al. (2000), que observaram um aumento de grãos de pólen degenerados e anteras estéreis quando o milho "Saracura" foi submetido a um forte e prolongado estresse por encharcamento a partir do estádio fenológico V6.

Os resultados para rendimento de grãos (Tabela 4) foram semelhantes àqueles verificados com os componentes do rendimento. A exemplo do que aconteceu com a altura da planta e da inserção da espiga e diâmetro do caule, o nível natural de cálcio no solo poderia estar adequado, não havendo, portanto, efeitos significativos dos tratamentos.

É importante destacar que o milho "Saracura", apesar de ser um material tolerante, sofreu influência do alto nível de umidade do solo imposto pelo encharcamento. Essa condição es- tressante fez com o que o "Saracura" apresentasse um decréscimo na produção de grão. Mesmo com essa redução em produtividade, não se pode ignorar a tolerância dessa cultivar ao encharcamento intermitente do solo. Esse fato foi ratificado por Parentoni et al. (1995), Souza et al. (2000) e Magalhães et al. (2000 e 2001), que, trabalhando com o milho "Saracura", concluíram que, apesar de ele tolerar o encharcamento, sua produtividade pode ser afetada em função da duração do estresse.

Plantas que se desenvolvem em condições de déficit de oxigênio têm o crescimento vegetativo e reprodutivo reduzidos significativamente, de forma que a permanência prolongada sob essa deficiência pode levá-las à morte (Crane \& Davies, 1988). Em baixa pressão de oxigênio, a expressão gênica é alterada e os produtos desses genes induzem mudanças metabólicas e/ ou morfológicas que permitem a sobrevivência das plantas por períodos de tempo não muito prolongados (Alves et al., 2000; Chang et al., 2000).

O cálcio é um elemento que participa de vários processos fisiológicos nos diferentes estádios de desenvolvimento das plantas. Sua atividade depende da concentração e da localização na célula. Ao contrário dos outros nutrientes, a maior proporção encontra-se localizada no apoplasto, estabilizando ligações entre as substâncias pécticas da parede celular, que, ao atuar como componente estrutural, influencia nos processos que levam ao crescimento celular (Seling et al., 2000). Trabalhos realizados com a aplicação de cálcio exógeno demonstraram que houve um aumento na concentração desse elemento na parede celular em condições de encharcamento (Subbaiah et al. 1994a e 1994b). Na literatura, são encontrados resultados em que a adição do $\mathrm{CaCl}_{2}$ atenua o efeito de outros sais, como o $\mathrm{NaCl}$, mas ainda não está claro como esse processo ocor- 


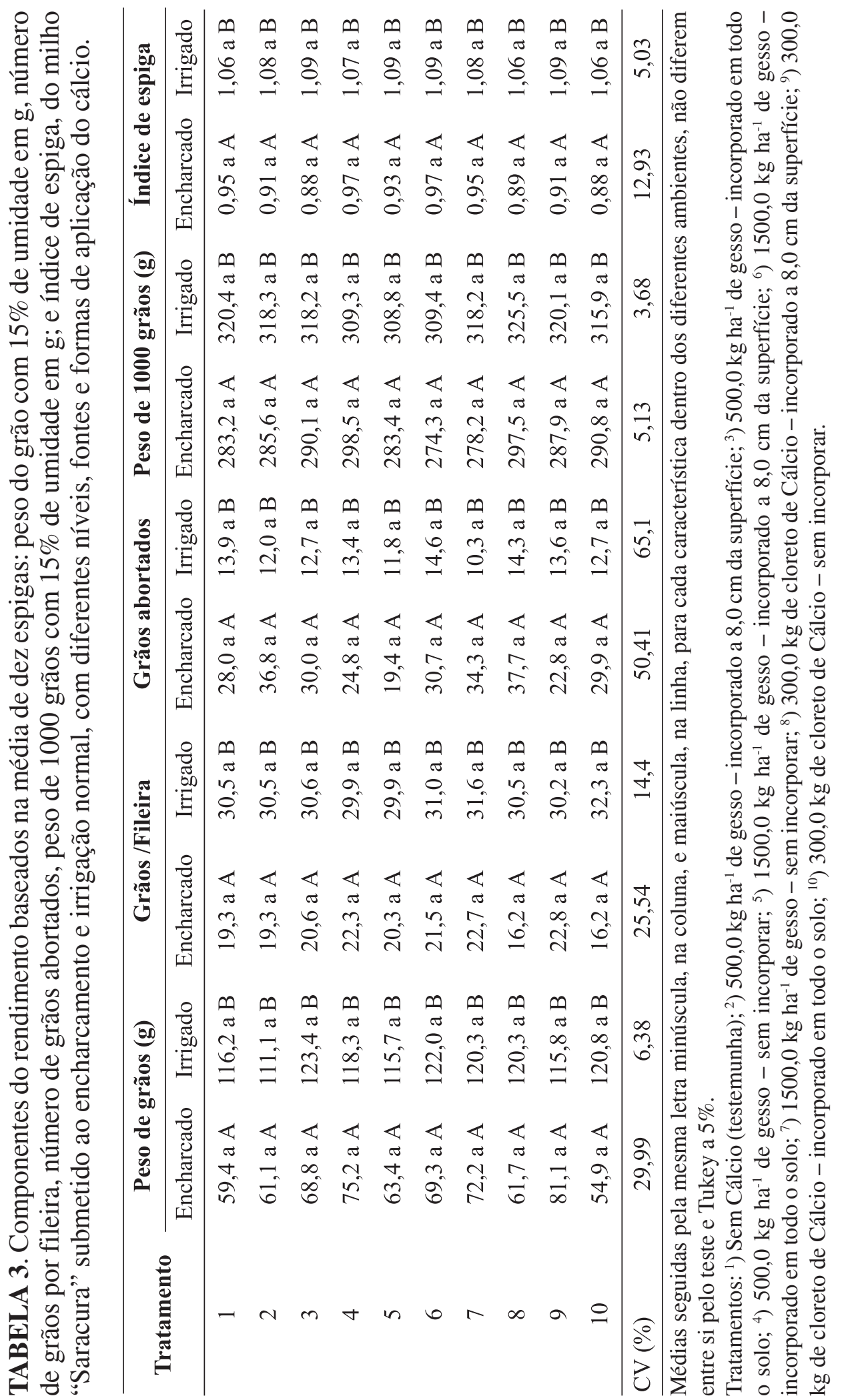


TABELA 4. Rendimento de grão $\left(\mathrm{kg} \mathrm{ha}^{-1}\right)$ com $15 \%$ de umidade, de milho "Saracura" submetido ao encharcamento e irrigação normal, com diferentes níveis, fontes e formas de aplicação do cálcio.

\begin{tabular}{ccc}
\hline & \multicolumn{2}{c}{ Rendimento de grão } \\
\cline { 2 - 3 } Tratamento $^{1}$ & \multicolumn{2}{c}{ Ambiente } \\
\cline { 2 - 3 } & Encharcado & Irrigado \\
\hline 1 & 4362,0 a A & 10381,0 a B \\
2 & 5869,0 a A & 10582,0 a B \\
4 & 6519,0 a A & 11037,0 a B \\
5 & 6812,0 a A & 11467,0 a B \\
6 & 5754,0 a A & 10508,0 a B \\
7 & 6148,0 a A & 10393,0 a B \\
8 & 6390,0 a A & 10573,0 a B \\
9 & 4950,0 a A & 9812,0 a B \\
10 & 6442,0 a A & 10114,0 a B \\
\hline CV $(\%)$ & 3717,0 a A & 10167,0 a B \\
\hline
\end{tabular}

$\left.{ }^{2}\right)$ Médias seguidas pela mesma letra minúscula, na coluna, e maiúscula, na linha, para cada característica dentro dos diferentes ambientes, não diferem entre si pelo teste e Tukey a 5\%.

$\left.{ }^{1}\right)$ Sem Cálcio (testemunha); $\left.{ }^{2}\right) 500,0 \mathrm{~kg} \mathrm{ha}^{-1}$ de gesso - incorporado a 8,0 cm da superfície; ${ }^{3}$ ) 500,0 kg ha-1 de gesso incorporado em todo o solo; ${ }^{4}$ ) 500,0 $\mathrm{kg} \mathrm{ha}^{-1}$ de gesso - sem incorporar; ${ }^{5}$ ) $1500,0 \mathrm{~kg} \mathrm{ha}^{-1}$ de gesso - incorporado a 8,0 cm da superfície; ${ }^{6}$ ) 1500,0 $\mathrm{kg} \mathrm{ha}^{-1}$ de gesso - incorporado em todo o solo; ${ }^{7}$ ) 1500,0 $\mathrm{kg} \mathrm{ha}^{-1}$ de gesso - sem incorporar; ${ }^{8}$ ) $300,0 \mathrm{~kg}$ de cloreto de Cálcio - incorporado a 8,0 cm da superfície; ${ }^{9}$ ) 300,0 kg de cloreto de Cálcio - incorporado em todo o solo; $\left.{ }^{10}\right) 300,0 \mathrm{~kg}$ de cloreto de Cálcio - sem incorporar.

re. $\mathrm{O}$ cálcio presente no $\mathrm{CaCl}_{2}$ é um nutriente conhecido por atuar na permeabilidade e na seletividade das membranas e na regulação da pressão de turgor das células (Purcino et al., 2001a).

Estudos com o milho "Saracura", em condições controladas de laboratório, mostraram uma maior sobrevivência das plântulas dessa cultivar quando submetida ao encharcamento na presença de cloreto de cálcio (Gouveia, 2001; Purcino et al., 2001b; Vitorino et al., 2001). Pelo exposto, não pode ser descartada a hipótese de que a tolerância do milho "Saracura" ao encharcamento, nas condições em que foi realizado o experimento, seja proveniente do efeito positivo do cálcio.

Entretanto, esses resultados não foram confirmados em condições de campo, no tipo de solo utilizado na presente pesquisa. É necessário testar outros solos, com menor teor de cálcio natural, assim como é importante atentar para a qualidade da água utilizada na irrigação. Sete Lagoas possui uma água com alto teor de calcá- 
rio, o que pode ter influenciado os resultados nesse tipo de estudo. Os resultados revelaram que os níveis, fontes e formas de aplicação de cálcio utilizados não influenciaram as variáveis de crescimento e rendimento avaliadas, em função, provavelmente, do conteúdo de cálcio que possuía o solo e da concentração de cálcio na água utilizada para irrigação.

\section{Conclusões}

O encharcamento do solo reduziu o crescimento e o rendimento das plantas, independente da presença do cálcio.

O teor de cálcio presente no solo provavelmente foi suficiente para garantir o crescimento e o rendimento das plantas, em condições de campo. Esse fato pode ter contribuído para que os tratamentos alagados não apresentassem diferenças significativas entre as variáveis avaliadas.

\section{Literatura Citada}

ALVES, J. D.; MAGALHÃES, M. M.; OLIVEIRA, L. E. M.; VITORINO, P. F. P. G. Mecanismo de tolerância de plantas ao encharcamento. Universa, Brasília, v. 8, n. 1, mar. 2000.

CHANG, W. W. P.; HUANG, L.; SHEN, M.; WEBSTER, C.; BURLINGAME, A. L.; ROBERTS, J. K. M. Patterns of protein synthesis and tolerance of anoxia in root tips of maize seedling acclimated to a low-oxygen environment, and identification of proteins by mass spectroetry. Plant Physiology, Rockville, v. 122, n. 2, p. 295317, Feb. 2000.

COELHO, C. H. M. Modificações fisiológicas e genéticas em ciclos de seleção no cultivar Brs 4154 tolerante ao encharcamento. 2004. 53 f. Dissertação (Mestrado) - Universidade Federal de Viçosa, Viçosa.
CRANE, J. H.; DAVIES, F. S. Periodic and seasonal flooding effects on survival, growth, and stomatal conductance of young Rabbiteye Blueberry plants. Journal of the American Society for Horticultural Science, Alexandria, v. 113, n. 4, p. 488-493, July 1988.

DAMARTY, M.; MORUAN, C.; THELLIER, M. Calcium and Cell. Plant Cell Environmental, Oxford, v. 7, p. 441-448, 1984.

FRIES, D. D.; ALVES, J. D.; DELÚ FILHO, N.; MAGALHÃES, P. C.; GOULART, P. F. P.; MAGALHÃES, M. M. Crescimento de plântulas do milho "saracura" (brs-4154) e atividade de aamilase e invertases associados ao aumento da tolerância ao encharcamento exercido pelo cálcio exógeno. Bragantia. Campinas, v. 66, n. 1, p. 1-9, 2007.

GOUVÊA, J. A. Crescimento inicial e sobrevivência do milho (Zea mays L.), cv. "Saracura" BR -154, em hipoxia sob condições de encharcamento. 2001. 33 f. Dissertação (Mestrado em Fisiologia Vegetal) - Universidade Federal de Lavras, Lavras.

GRANT, G. T.; MORRIS, D. A.; REES, P. J. P.; SMITH, K. A. Biological interactions between polysaccharides and divalent cations: The eggbox model. FEBS Letters, Amsterdam, v. 32, n. 1, p. 195-198, 1973.

LIAO, C. T.; LIN, C. H. Physiological adaptation of crop plants to flooding stress. Proceedings of the National Science Council, ROC (B), , Taiper, v. 25, n. 3 , p. $148-157,2001$.

MAGALHÃES, P. C.; DURÃES, F. O. M.; ANDRADE, C. de L. T. de ; OLIVEIRA, A. C. de; 
GAMA E. E. G. Adaptação do milho a diferentes condições de encharcamento. In: CONGRESSO NACIONAL DE MILHO E SORGO, 23., 2000, Uberlândia. A inovacao tecnologica e a competividade no contexto dos mercados globalizados: resumos expandidos. Sete Lagoas: ABMS/Embrapa Milho e Sorgo/Universidade Federal de Uberlandia, 2000. CD ROM.

MAGALHÃES, P. C.; DURÃES, F. O. M.; ANDRADE, C. de L. T. de; OLIVEIRA, A. C. de; SOUZA, I. R. P. de; GAMA E. E. G. Adaptação do milho a diferentes condições de encharcamento. In: CONGRESSO NACIONAL DE FISIOLOGIA VEGETAL, 8., 2001, Ilhéus. Resumos expandidos... Ilhéus: CNFV, 2001. CDROM.

MAGALHÃES, P. C.; SOUZA, I. R. P. de; DURÃES, F. O. M.; KARAM, D.; OLIVEIRA, A. C. de. Efeitos do cálcio e do encharcamento do solo na proteína e na porosidade de raízes de milho "Saracura". In: In: CONGRESSO NACIONAL DE MILHO E SORGO, 26.; SIMPÓSIO BRASILEIRO SOBRE A LAGARTA-DO-CARTUCHO, SPODOPTERA FRUGIPERDA, 2.; SIMPÓSIO SOBRE COLLETOTRICHUM GRAMINICOLA, 1., 2006, Belo Horizonte, Inovação para sistemas integrados de produção: trabalhos apresentados. \{Sete Lagoas\}: ABMS, 2006. 1 CD-ROM.

PARENTONI, S. N.; GAMA, E. E. G.; MAGNAVACA, R.; MAGALHÃES, P. C. Seleção para tolerância ao encharcamento em milho (Zea mays L.) In: SIMPÓSIO INTERNACIONAL SOBRE ESTRESSE AMBIENTAL, 1., 1992, Belo Horizonte. O milho em perspectiva: anais. Sete Lagoas: EMBRAPA-CNPMS; Mexico: CIMMYT, 1995. p. 433-449.
PARENTONI, S. N.; GAMA, E. E. G.; LOPES, M. A.; SANTOS, M. X. dos; GUIMARÃES, P. E. de O; PACHECO, C. A.. P.; MEIRELLES, W. F.; SOUZA, I. R. P. de; CORREA, L. A. Nove ciclos de seleção para tolerância ao encharcamento na variedade de milho CMS-54 "Saracura". In: CONGRESSO BRASILEIRO DE MILHO E SORGO, 22., 1998, Recife. Resumos... Recife: ABMS, 1998. p.12.

PURCINO, R. P.; ALVES, J. D.; MAGALHÃES, M. M.; SILVEIRA, T.; FRIES, D. Efeito do cloreto de cálcio na germinação de sementes de milho da variedade BR-154 "Saracura" In: CONGRESSO BRASILEIRO DE FISIOLOGIA VEGETAL, 8., 2001, Ilhéus. Anais... Ilhéus: SBFV, 2001a. CD-ROM.

PURCINO, R. P.; ALVES, J. D.; MAGALHÃES, M. M.; SILVEIRA, T.; FRIES, D. Efeito fisiológico do cálcio na germinação de sementes de milho da BR-154 "Saracura" e na tolerância das plântulas ao encharcamento. In: CONGRESSO BRASILEIRO DE FISIOLOGIA VEGETAL, 8., 2001, Ilhéus. Anais.... Ilhéus: SBFV, 2001b. CDROM.

RIBEIRO, A. C.; GUIMARÃES, P. T. G.; ALVAREZ V.; V. H. (Ed.). Recomendações para o uso de corretivos e fertilizantes em Minas Gerais - 5a. aproximação. Vicosa: 1999. 359 p.

SANTOS, A. B. dos. Aproveitamento da soca. In: Vieira, N. R. de A.; Santos, A.B. dos; Sant' Ana, E. P. (Ed.). A cultura do arroz no Brasil. Santo Antônio de Goiás: Embrapa Arroz e feijão, 1999. p. 463-492.

SELING, S.; WISSEMEIER, A. H.; CAMBIER, P.; CUTSEM, P. V. Calcium deficiency in potato 
(Solanum tuberosum ssp. tuberosum) leaves and its effects on the pectic composition of the apoplastic fluid. Physiologia Plantarum, Copenhagem, v. 109, n. 1, p. 44-50, May 2000.

SISTEMA brasileiro de classificação de solos. Brasília, DF: Embrapa Produção de Informação; Rio de Janeiro: Embrapa Solos, 1999. 412 p.

SOUZA, I. R. P. de; MAGALHÃES, P. C.; MEYER, L. E.; PIRES, N. M.; ANDRADE, C. L. T. de. Alterações morfo-fisiológicas no grão de pólen e atividade da álcool desidrogenase em milho sob diferentes frequiências de encharcamento. In: CONGRESSO NACIONAL DE MILHO E SORGO, 23., 2000, Uberlândia. A inovação tecnológica e a competividade no contexto dos mercados globalizados: resumos expandidos. Sete Lagoas: ABMS/Embrapa Milho e Sorgo/Universidade Federal de Uberlandia, 2000. CD ROM.

SUBBAIAH, C. C.; BUSH, D. S.; SACHS, M. M. Elevation of cytosolic calcium precedes anoxic gene expression in maize suspension cultured cells. The Plant Cell, Rockville, v. 6, n. 12, p. 1747-1762, Dec. 1994a.

SUBBAIAH, C. C.; ZHANG, J.; SACHS, M. M. Involvement of intracellular calcium in anaerobic gene expression and survival of maize seedlings. Plant Physiology, Rockville, v. 105, n. 1, p. 369376, May 1994b.

SUMMERS, J. E.; RATCLIFFE, R. G.; JACKSON, M. B. Anoxia tolerance in the aquatic monocot potamogeton pectinatus: absence of oxygen stimulates elongation in association with an unusually large Pasteur effect. Journal of Experimental Botany, Oxford, v. 51, n. 349, p. 1413-1422, Aug. 2000.

VITORINO, P. G.; ALVES, J. D.; MAGALHÃES, P. C.; MAGALHÃES, M. M.; LIMA, L. C. O.; OLIVEIRA, L. E. M. Flooding tolerance and cell wall alterations in maize mesocotyl during hypoxia. Pesquisa Agropecuária Brasileira Brasilia, Brasília, DF, v. 36, n. 8, p. 1027-1035, ago. 2001. 